\title{
División sexual del trabajo y confinamiento en jóvenes de preparatoria. Un estudio de caso de Aguascalientes, México*
}

\author{
DOI: https://doi.org/10.18046/recs.i35.4882
}

\section{Sexual Division of Labor and Confinement among High School Students. A Case Study from Aguascalientes, Mexico}

\author{
Nancy Chávez-Llamas ${ }^{* *}$ \\ Centro de Investigación y Docencia Económicas (Aguascalientes, México) \\ Angélica Ospina-Escobar*** \\ Centro de Investigación y Docencia Económicas (Aguascalientes, México)
}

\begin{abstract}
* Artículo de investigación producto parcial de un proyecto en curso, denominado "Understanding Drug Consumption in Teenagers and Young Adults: Protocol for Prevention and Treatment Intervention", que comenzó en enero de 2019 y fue financiado por Open Society Foundations. Artículo de investigación recibido el 01.07.2O21 y aprobado el 27.09.2021.

** Licenciada en Psicología por la Universidad Autónoma de Zacatecas (México) y Maestra en Investigaciones Sociales y Humanísticas por la Universidad Autónoma de Aguascalientes (México). Asistente de investigación en el Programa de Política de Drogas del Centro de Investigación y Docencia Económicas, Región Centro (México). Sus temas de investigación son jóvenes, violencia, drogas, narcotráfico, narcocultura y vida cotidiana. Correo electrónico: nancy.estrella@ cide.edu ORCID: https://orcid.org/oooo-0oo2-7347-9871

*** Doctora en Estudios de Población y Maestra en Demografía por El Colegio de México (México). Catedrática Conacyt asignada al Programa de Política de Drogas del Centro de Investigación y Docencia Económicas, Región Centro (México). Sus temas de investigación son el uso problemático de drogas, reducción de daños, género, curso de vida y sociología de las emociones. Correo electrónico: angelica.ospina@cide.edu ORCID: https://orcid.org/oooo-0oo3-0768-5252
\end{abstract}




\section{Cómo citar/How to cite}

Chávez-Llamas, Nancy; Ospina-Escobar, Angélica (2021). División sexual del trabajo y confinamiento en jóvenes de preparatoria. Un estudio de caso de Aguascalientes, México.

Revista CS, 35, 41-66. https://doi.org/10.18046/recs.i35.4882 


\section{Resumen}

Este estudio de caso cualitativo, derivado de un trabajo etnográfico realizado entre agosto de 2019 y julio de 2020, describe cómo un grupo de jóvenes estudiantes de una preparatoria pública de Aguascalientes, México, experimentó el confinamiento por COVID-19. La contingencia generó una intensificación de la división sexual del trabajo entre los participantes: mientras las mujeres aumentaron su participación en el trabajo doméstico y de cuidados, los hombres incrementaron su participación en el trabajo de la construcción. Estos últimos desertaron en mayor medida de la escuela que las mujeres, lo que podría significar que las tareas domésticas no remuneradas se logran compatibilizar mejor con las tareas académicas en comparación con las ocupaciones remuneradas extradomésticas. La falta de protección social de las juventudes en México favoreció el aumento de las inequidades de género en los hogares durante el confinamiento, afectando la salud mental de los jóvenes y su autonomía.

\section{PALABRAS CLAVE:}

jóvenes, división sexual del trabajo, COVID-19, inequidades de género, México

This qualitative case study describes how a group of young students from a public high school in Aguascalientes (Mexico) experienced the confinement for the COVID-19 pandemic. Our main finding is the intensification of the sexual division of labor. While women intensified their domestic and care work participation, men were pushed to enter the informal labor market to support their household economy. Men dropped out of school to a greater extent than women, which could mean that unpaid household chores are more compatible with academic tasks compared to paid extra-domestic occupations. The lack of social protection for youth in Mexico exacerbates gender inequalities among young men and women during confinement, impacting their mental health and their autonomy. The paper is based on an ethnographic experience conducted in a public high school from August 2019 to July 2020.

\section{KEYWORDS:}

Youths, Sexual Division of Labor, COVID-19, Gender Inequalities, Mexico 



\section{Introducción}

En marzo del 2020, tras la llegada a México del virus SARS-CoV-2 (en adelante, COVID-19), el gobierno federal implementó varias medidas para confinar a la población, entre ellas la suspensión por parte de la Secretaría de Educación Pública (SEP) de clases en modalidad presencial y el tránsito a modalidad remota tomada desde el 17 de marzo (SEP, 2020). Bajo tal esquema culminó el ciclo escolar que terminó en julio de ese año e inició el nuevo ciclo escolar en septiembre de 2020.

De acuerdo con datos del Consejo Nacional de Evaluación de la Política de Desarrollo Social (Coneval, 2020a), las medidas de confinamiento tomadas para enfrentar la amenaza a la salud pública por la pandemia de la COVID-19 causaron una contracción importante de la economía; esta afectó principalmente a los hogares más pobres a causa de la pérdida de sus fuentes de empleo, o bien de la disminución de sus ingresos (Coneval, 202ob). Por ejemplo, entre febrero y mayo del 2020 los ingresos en los hogares mexicanos donde residen niños se redujeron en un $73,5 \%$ frente a $57,7 \%$ en hogares sin niños (Fondo de las Naciones Unidas para la Infancia - Unicef, 2020).

Además de constreñimientos económicos, el confinamiento convirtió los hogares en el epicentro de múltiples actividades domésticas, laborales y escolares que afectaron las dinámicas de uso del tiempo de sus miembros. Entre ellas se destaca la carga de trabajo doméstico y de cuidados no remunerados que suelen realizar en mayor medida las mujeres, especialmente en los hogares con menor escolaridad acumulada y menor nivel de ingresos (Casique, 2008; Pedrero, 2004; Scuro-Somma, 2009).

En este artículo analizamos cómo el confinamiento por COVID-19 afectó de manera diferenciada las dinámicas de uso de tiempo de varones y mujeres jóvenes que son estudiantes de una preparatoria pública de Aguascalientes (México). El objetivo es describir cómo los jóvenes participantes del estudio distribuyeron sus tiempos durante el contexto de confinamiento por COVID-19 y las implicaciones que ello tuvo principalmente en su salud mental y el abandono escolar. El uso del tiempo se concibe aquí como una categoría analítica para estudiar las consecuencias sociales de la pandemia en el ámbito específico de las desigualdades de género.

\section{Tiempo, género y desigualdad social}

Partimos de la concepción del tiempo como recurso finito fundamental de los sujetos, cuya disponibilidad o carencia afecta directamente su calidad de vida presente y sus opciones de vida (Damián, 2003; Aguirre, 2009). 
La literatura sociodemográfica muestra que el tiempo es un recurso especialmente importante para los hogares pobres en periodos de crisis económicas, entre otras cosas porque durante las contingencias los hogares con menos ingresos buscan la obtención de recursos monetarios a través de la inserción de un mayor número de sus miembros en el mercado laboral, realizan acuerdos de convivencia para optimizar los recursos existentes y participan en relaciones de intercambio y reciprocidad para garantizar su sobrevivencia (Barbieri; De Oliveira, 1989). Estas estrategias acarrean cambios en las dinámicas de uso del tiempo de los miembros del hogar que serán evaluadas y negociadas en función de la posición social de cada uno de ellos. Esta última, a su vez, está condicionada por factores como la edad y el género.

La edad, en tanto construcción social, se experimenta en el marco de un conjunto de reglas y mecanismos que regulan la extensión temporal de la vida (Riley, 1987), y desde el cual se asignan expectativas y normas sociales a los sujetos, basadas en su edad cronológica. Al interior de los hogares, la posición generacional de los sujetos define el lugar de un individuo en la matriz de la familia extendida y da forma a identidades, roles y responsabilidades (Riley, 1987) que, a su vez, suponen unas maneras esperadas de uso del tiempo. Los jóvenes participantes de este estudio tienen entre 15 y 19 años, por lo que las expectativas de sus padres/madres/tutores con respecto a continuar en la escuela o ingresar al mercado laboral se tornan fundamentales, en tanto condicionan el grado de apoyo que reciben para cumplir con sus obligaciones escolares (Gaxiola-Romero; González-Lugo, 2017) y, así mismo, el grado de presión que reciben para ingresar al mercado laboral o ayudar con las tareas domésticas y de cuidado no remuneradas en el hogar.

Por género entendemos el conjunto de "prácticas, símbolos, representaciones, normas y valores sociales que las sociedades elaboran a partir de la diferencia anatomo-fisiológica y que dan sentido [...] al relacionamiento de las personas en tanto sujetos sexuados" (De Barbieri, 1993: 192). Entendido así, el género impone una serie de normas sociales en torno al uso del tiempo de acuerdo con las representaciones sociales de lo masculino y lo femenino, y las actividades que son consideradas propias de varones y mujeres, de tal manera que refuerza y perpetúa asimetrías en las relaciones de poder y en la posesión de recursos materiales, sociales y simbólicos, y de privilegios (Aguirre, 2009; De Barbieri, 1991). Uno de los mecanismos a través de los cuales el sistema sexo/género sedimenta las desigualdades entre varones y mujeres es la división sexual del trabajo que corporiza las asimetrías de poder entre unos y otras, asegurando su distancia social (Aguirre, 2009; De Oliveira; Ariza, 2000; Eisenstein, 1999; Valenzuela, 2003). 
En ese marco, la división sexual del trabajo asigna la responsabilidad de la proveeduría económica a los varones y el trabajo doméstico no remunerado ${ }^{1}$ y de cuidados$^{2}$ a las mujeres (Eisenstein, 1999; Scuro-Somma, 2009). El primero se realiza en el espacio extradoméstico; el segundo, en el doméstico. Mientras que el tiempo destinado al mercado de trabajo se mercantiliza, el tiempo destinado al trabajo doméstico se convierte en un recurso moral que otorga propiedades de bueno o malo a quien lo realiza o a quien se resiste (Aguirre, 2009; Batthyány, 2009).

Así, la división sexual del trabajo institucionaliza la interacción con otros y otorga una identidad social ligada a formas específicas de performar el género. De ahí que mientras el trabajo remunerado suele ser central en la construcción de las identidades masculinas como proveedores (Martínez; Ferraris, 2017), la identidad de género de las mujeres se construye principalmente en términos de su potencialidad para brindar cuidados (Eisenstein, 1999; Batthyány, 2009). Este proceso refuerza la feminización del trabajo doméstico y de cuidados y naturaliza el rol de cuidadoras en las mujeres. Con la nueva normalidad implementada con el inicio de la pandemia por COVID-19, la feminización del trabajo se agudizó en la mayoría de los hogares, limitando a las mujeres en su autonomía y derechos (Entidad de las Naciones Unidas para la Igualdad de Género y el Empoderamiento de las Mujeres - ONU Mujeres; Comisión Económica para América Latina - Cepal, 2020)

Si bien la división sexual del trabajo supone las dicotomías remunerado/no remunerado, público/privado, proveer/cuidar, etc., existe una relación funcional entre los elementos que las conforman, pues uno y otro se afectan mutuamente, estableciendo relaciones sustitutivas y complementarias (Pedrero, 2004). Tanto el trabajo remunerado extradoméstico como el doméstico y de cuidados no remunerado supone, para las mujeres y los varones, costos monetarios y no monetarios de uso de tiempo, malestares y renuncias particulares (Carrasco, 2003). Las negociaciones de los miembros de la familia en torno a quién debe realizar uno u otro trabajo son complejas y contradictorias. Por ello, su análisis requiere comprender los contextos particulares en los que tienen lugar las relaciones entre varones y mujeres, en función de los roles de los miembros del hogar y las características de los hogares (Pedrero,

1. Por trabajo doméstico no remunerado es aquel que es realizado por integrantes del hogar e incluye tareas como "compra de bienes y adquisición de servicios para el hogar, cocinar, limpiar la casa, lavar, planchar, cuidar mascotas y plantas, organización y gestión de tareas, pagar cuentas, realizar trámites” (Aguirre, 2009: 34).

2. El trabajo de cuidados se define como la acción de cuidar a niños, adultos o ancianos para el desarrollo y bienestar de su vida cotidiana. Implica un trabajo material, pero también una dimensión emocional y afectiva. Incluye tareas de cuidado, el juego, llevarlos a pasear, ayudarlos en los deberes y socializarlos, atención a las necesidades fisiológicas, médicas y sociales (Aguirre, 2009: 35). 
2004), con la finalidad de reconocer, redistribuir y reducir la carga laboral impuesta, sobre todo, en las mujeres (ONU Mujeres; Cepal, 2O2O), pues la literatura muestra que el tamaño y tipo de hogares, la etapa del ciclo de vida, el nivel de ingresos y la escolaridad de los miembros son factores que inciden en la división sexual del trabajo al interior de estos (Aguirre, 2009; Batthyány, 2009; Casique, 2008; Pedrero, 2004).

En este análisis nos preguntamos cómo, en el contexto de fragilidad e inseguridad que supuso para los hogares pobres la llegada de CoviD-19, se transformaron o intensificaron las dinámicas de división sexual del trabajo al interior de los hogares, y sus efectos en la salud mental de un grupo de jóvenes (hombres y mujeres) estudiantes de una preparatoria pública del municipio de Jesús María, en el estado de Aguascalientes. Al respecto, estudiamos las diferencias en el uso del tiempo como expresión de desigualdades para el desarrollo de capacidades y oportunidades entre hombres y mujeres jóvenes pobres, en el marco más amplio de la desigualdad estructural, la incertidumbre y el desencanto que experimentan millones de adolescentes en México (Busso, 2001; Reguillo, 2004; Valenzuela, 2015).

\section{Metodología}

El trabajo mostrado aquí es un estudio de caso cuyo propósito fue profundizar en las experiencias de confinamiento de un grupo de jóvenes (Yin, 2003); presta especial atención al análisis de las modificaciones que experimentaron en su vida cotidiana y uso del tiempo a partir del encierro.

Los participantes del estudio fueron cuatro mujeres y tres hombres, con edades comprendidas entre 16 y 19 años, estudiantes del turno matutino de un bachillerato técnico semiurbano del municipio de Jesús María (Aguascalientes). Los siete jóvenes provienen de hogares pobres, cuyos padres/madres o tutores tienen un nivel de escolaridad máxima de secundaria completa, que se ocupan en labores manuales de baja calificación (obreros de maquiladora, albañiles, dependientes de mostrador, vendedores informales) y reciben ingresos de hasta tres salarios mínimos mensuales ${ }^{3}$. La mayoría de los jóvenes participantes (5/7), además de estudiar, trabajaban para aportar a la economía de sus hogares y residían en colonias que percibían peligrosas debido a sus altos índices de criminalidad y consumo de sustancias psicoactivas ilegales (Ospina-Escobar; Chávez-Llamas, 2020) ${ }^{4}$.

3. Desde el 1 de enero de 2021, el salario mínimo diario en México corresponde a 213,39 pesos mexicanos (10 USD, aproximadamente).

4. Como parte del estudio más amplio en el que se inscribe este análisis, se levantó una encuesta de caracterización de los hogares y estudiantes de la escuela donde este realizó. Los resultados muestran que 
El cuadro 1 resume algunas características de los participantes, las cuales permiten plantear que se trata de jóvenes que constituyen casos típicos ${ }^{5}$ de adolescentes que asisten a escuelas preparatorias públicas técnicas de colonias populares de Aguascalientes (Martínez, 2012). Esto permite profundizar en las experiencias de personas que se consideran promedio de la población de interés (Creswell, 1998).

La selección de los participantes se realizó a partir de un trabajo etnográfico realizado entre agosto y diciembre de 2019 en la escuela preparatoria donde recibían sus clases, y en el marco de un estudio más amplio: en este, los siete jóvenes participantes estaban siendo capacitados como promotores pares para prevención del uso de sustancias psicoactivas (Ospina-Escobar; Chávez-Llamas, 2020).

El director de la escuela brindó la autorización para establecer contacto con los jóvenes y firmó el consentimiento informado para poder realizar el estudio. Los participantes fueron informados del estudio y dieron su consentimiento informado de manera verbal. Los padres/madres o tutores legales fueron informados del estudio y dieron su consentimiento verbal al director de la escuela.

Tras la suspensión de las clases presenciales, se continuó el acompañamiento al grupo de pares, con quienes las autoras habían establecido relaciones de confianza y afecto. Este acompañamiento se realizó a través de llamadas telefónicas y mensajes por WhatsApp, lo que permitió mantener el contacto hasta julio del 2020 cuando finalizó el ciclo escolar. La comunicación con los jóvenes se sistematizó en diarios de campo, al igual que se hizo con la comunicación sostenida con la psicóloga de la escuela, con quien intercambiábamos de manera regular información sobre la situación académica, familiar y emocional de los jóvenes participantes. Los nombres reales fueron reemplazados por seudónimos para proteger y garantizar la confidencialidad de los participantes.

Para la sistematización y análisis de la información se siguió una perspectiva fenomenológica hermenéutica (Fuster, 2019), que permite describir e interpretar las experiencias vividas desde el punto de vista del actor a través del análisis de relatos, historias y anécdotas (Chase, 2005). El material de campo fue codificado usando el programa Atlas.Ti a partir de la construcción de seis categorías analíticas: habilidades

la presencia de pandillas, venta y consumo de drogas son las principales problemáticas que identifican los jóvenes en sus vecindarios. El 44\% de los encuestados reportó trabajar además de estudiar ( $52 \%$ de los varones y $34 \%$ de las mujeres). Uno de cada cuatro jóvenes encuestados $(20,4 \%)$ reportó que en los 12 meses previos alguna discusión entre miembros de su familia había terminado en golpes. En términos de uso de sustancias, el 85\% declaró haber ingerido alcohol alguna vez en su vida y el 22\% reportó haber consumido alguna sustancia ilegal (Ospina-Escobar; Chávez-Llamas, 2020).

5. Por casos típicos se entiende un tipo de muestreo en estudios cualitativos que se enfoca en las características promedio, o en aquellas más recurrentes en la población mayor que se estudia (Martínez, 2012). 
y recursos individuales, recursos del hogar, contexto social, uso del tiempo, sociabilidad y afrontamiento. En este artículo solo presentamos los hallazgos referidos a los cambios en el uso del tiempo.

\begin{tabular}{|l|l|}
\hline CUADRO 1 & Características sociodemográficas de los participantes del estudio \\
\hline
\end{tabular}

\begin{tabular}{|c|c|c|c|c|c|c|c|}
\hline ID & Edad & $\begin{array}{c}\text { Grado } \\
\text { escolar } \\
\text { (semestre) }\end{array}$ & $\begin{array}{l}\text { Personas } \\
\text { con } \\
\text { quienes } \\
\text { vive }\end{array}$ & $\begin{array}{c}\text { N. } \\
\text { Dep. } \\
\text { hogar* }^{*}\end{array}$ & $\begin{array}{c}\text { Ocupación } \\
\text { de los } \\
\text { padres/ } \\
\text { tutores }\end{array}$ & $\begin{array}{c}\text { Trabaja/ } \\
\text { ocupación }\end{array}$ & $\begin{array}{l}\text { Vínculos } \\
\text { familiares }\end{array}$ \\
\hline Lety & 19 & $6 .^{\circ}$ & $\begin{array}{l}\text { Padres y } \\
\text { hermano } \\
\text { mayor }\end{array}$ & 2 & $\begin{array}{l}\text { Madre venta de } \\
\text { comida, padre } \\
\text { desocupado }\end{array}$ & $\begin{array}{l}\text { Venta de } \\
\text { productos de } \\
\text { belleza }\end{array}$ & $\begin{array}{c}\text { Discusiones } \\
\text { constantes, } \\
\text { abandono del } \\
\text { hogar }\end{array}$ \\
\hline Ely & 17 & $6 .^{\circ}$ & $\begin{array}{l}\text { Padres y tres } \\
\text { hermanos } \\
\text { mayores, } \\
\text { sobrina }\end{array}$ & 2 & $\begin{array}{c}\text { Madre ama } \\
\text { de casa, padre } \\
\text { agricultor }\end{array}$ & $\begin{array}{l}\text { Antes } \\
\text { asistente en } \\
\text { consultorio } \\
\text { dental }\end{array}$ & $\begin{array}{c}\text { Buena relación } \\
\text { con hermanos y } \\
\text { padres }\end{array}$ \\
\hline Ana & 16 & $4 .^{\circ}$ & $\begin{array}{l}\text { Padres y dos } \\
\text { de cuatro } \\
\text { hermanos }\end{array}$ & 2 & $\begin{array}{l}\text { Madre venta de } \\
\text { frituras, padre } \\
\text { mecánico }\end{array}$ & $\begin{array}{l}\text { Venta de } \\
\text { frituras con la } \\
\text { madre, venta } \\
\text { de calzado }\end{array}$ & $\begin{array}{c}\text { Relación cercana } \\
\text { con madre y } \\
\text { hermana }\end{array}$ \\
\hline Mary & 15 & $2 .^{\circ}$ & $\begin{array}{l}\text { Padres y tres } \\
\text { hermanas } \\
\text { menores }\end{array}$ & 3 & $\begin{array}{c}\text { Padre obrero, } \\
\text { madre venta } \\
\text { comidas en } \\
\text { calle }\end{array}$ & $\begin{array}{l}\text { No trabaja } \\
\text { por fuera del } \\
\text { hogar }\end{array}$ & $\begin{array}{c}\text { Buena relación } \\
\text { con el padre y } \\
\text { hermanas }\end{array}$ \\
\hline Paco & 16 & $4 .^{\circ}$ & Tíos y prima & 2 & $\begin{array}{l}\text { Tío jubilado y } \\
\text { tía ama de casa }\end{array}$ & $\begin{array}{l}\text { Manteni- } \\
\text { miento y } \\
\text { construcción }\end{array}$ & $\begin{array}{c}\text { Separación de } \\
\text { padres, abandono }\end{array}$ \\
\hline Carlos & 17 & $6 .^{\circ}$ & $\begin{array}{l}\text { Padres y dos } \\
\text { hermanos }\end{array}$ & 2 & $\begin{array}{l}\text { Padre área de } \\
\text { mantenimien- } \\
\text { to, madre ama } \\
\text { de casa }\end{array}$ & Construcción & $\begin{array}{l}\text { Distanciamiento } \\
\text { con el padre por } \\
\text { alcoholismo, } \\
\text { abandono } \\
\text { económico }\end{array}$ \\
\hline Pepe & 17 & $2 .^{\circ}$ & $\begin{array}{c}\text { Padres, } \\
\text { hermanos }(3) \\
\text { y cuñada }\end{array}$ & 5 & $\begin{array}{c}\text { Madre ama } \\
\text { de casa, Padre } \\
\text { desempleado }\end{array}$ & Construcción & $\begin{array}{c}\text { Mala relación con } \\
\text { madre, violencia } \\
\text { y distanciamiento } \\
\text { del padre, } \\
\text { consumo } \\
\text { problemático }\end{array}$ \\
\hline
\end{tabular}

Fuente: elaboración propia. al hogar y que requieren apoyo de cuidados como niños y adultos mayores. 


\section{Hallazgos}

\section{Contexto social}

Según datos del Instituto Nacional de Estadística y Geografía (Inegi, 2021), Jesús María es el segundo municipio más poblado de Aguascalientes, con poco menos de 130 ooo habitantes. El 24,7 \% de ellos tiene entre 12 y 24 años; el $25 \%$ vive en situación de pobreza; y el $38 \%$ se considera población vulnerable por carencias sociales (Coneval, 2020c). En este contexto, $40 \%$ no tiene acceso a internet y 52,8 \% no tiene computadores (de escritorio o portátiles) ni tabletas digitales (Inegi, 2021).

La escuela en que desarrollamos el estudio es una preparatoria técnica que, durante el ciclo escolar 2019-2020, tuvo 681 estudiantes matriculados. Los datos de una encuesta levantada entre estudiantes en febrero de 2020 revelan que la mayoría vive en casa propia $(88,8 \%) ; 81,6 \%$ vive en hogares nucleares donde el papá es el principal proveedor; y las madres de 59,2 \% trabajan fuera de su hogar. El 80,3\% de los participantes identifican a la madre como su principal cuidadora (Ospina-Escobar; Chávez-Llamas, 2020).

En el caso de Aguascalientes, la pandemia de la COVID-19 dio lugar a pérdida de empleos formales, aumento en las tasas de desocupación e informalidad labo$\mathrm{ral}^{6}$, situación que tuvo mayor impacto en trabajadores de bajos ingresos (hasta tres salarios mínimos) (México Cómo Vamos, 2020). Los hogares de los jóvenes participantes del estudio estuvieron afectados por estas circunstancias y ante ello, la estrategia de sobrevivencia familiar principal fue usar el tiempo de los adolescentes en beneficio de la economía familiar, situación que fue vivida de manera diferencial según la condición de género.

\section{El reforzamiento de los mandatos de género durante el confinamiento}

Aunque el confinamiento marcó un antes y un después en la organización de las actividades cotidianas de todos los participantes, la condición de género emergió en los relatos como el principal elemento diferenciador de las experiencias vividas. En particular, observamos que el confinamiento generó un reforzamiento de la separación entre el espacio doméstico y el espacio público entre hombres y mujeres jóvenes: las mujeres experimentaron mayor presión para permanecer en el espacio

6. Durante el tercer trimestre del 2020 se reportaron una tasa de desocupación del 5,6\% y una tasa de informalidad laboral de 41,6\% (Inegi, 202O). De marzo a junio de 202O disminuyó en 4,9\% el registro de empleos formales en el Instituto Mexicano del Seguro Social (IMSS, 2020). 
privado del hogar (cumplir con los deberes domésticos lleva implícito el quedarse en casa); mientras que en el caso de los varones, la necesidad de apoyar económicamente sus hogares los llevó a permanecer durante la mayor parte del tiempo en la calle.

No se me hace tan raro permanecer en cuarentena, antes de esta situación no salía mucho. En casa hago el quehacer, después comienzo a hacer tareas, también le ayudo a mis hermanas con sus tareas y pues en eso se me va súper rápido el día. (Mary, 15 años, 2. ${ }^{\circ}$ semestre, comunicación personal. 22.04.2020)

Esta separación de los espacios en función del género reforzó, entre otras cosas, la división público/privado asociada a los roles tradicionales de género, según la cual a las mujeres les corresponde apoyar las labores de crianza y cuidado, y por tanto, deben quedarse en casa (Pateman, 1996); mientras que la función natural de los varones es proveer y, por tanto, les corresponde salir al espacio público.

Yo tengo que hacer algo, no puedo simplemente ver cómo mi mamá batalla por darnos de comer a todos. Soy el mayor y me toca responderle. No es que ella me lo diga, es que es mi deber como hombre de la casa. (Pepe, 17 años, 2. ${ }^{\circ}$ semestre, comunicación personal, 16.04.2020)

En todos los casos encontramos que esta división sexual del trabajo causó conflictos y resistencias por parte de los jóvenes, en especial por la renuncia que les significó la intensificación de sus obligaciones frente a sus tiempos y espacios de ocio, de socialización con pares y de realización de actividades escolares. Sin embargo, observamos que hombres y mujeres expresaron de manera distinta dichas resistencias y que tanto en unas como en otros, el acceso a recursos de diverso tipo al interior de los hogares amortiguó las tensiones generadas por este aumento en las obligaciones. Además, encontramos que la estructura de los hogares y su ciclo de vida fueron elementos que pronunciaron o menguaron dichas tensiones.

\section{Las jóvenes y la experiencia del espacio doméstico}

Antes de iniciar la pandemia, Mary salía poco de su casa y su principal espacio de socialización era la escuela, debido, principalmente, al control que ejercía su padre en relación con los espacios y amistades que frecuentaba, y al que ejercía su madre al asignarle el cuidado de sus hermanas menores'. Así, una vez que Mary salía de la escuela, debía regresar a casa a realizar trabajos de cuidado.

7. Con edades de 1, 6 y 10 años. 
Con el inicio del confinamiento, Mary vivió una intensificación de sus responsabilidades de cuidado en su hogar, ya que ambos padres se vieron forzados a trabajar fuera de casa ante la disminución de los ingresos del padre. Las obligaciones de Mary eran las mismas (cuidar a sus hermanas menores, hacer el quehacer), pero ahora debía cumplirlas sin supervisión y apoyo de su madre, y con el requerimiento adicional de asistir a dos de sus hermanas menores en sus tareas escolares. La intensidad del trabajo emocional que conlleva el cuidado de niños pequeños (Hochschild, 2008), aunada a la presión por el descuido de las propias tareas, se expresó, en el caso de Mary, en la sensación corporal de un cansancio constante y dificultad para conciliar el sueño.

Yo me siento más cansada ahora, aunque me levanto tarde... También es que me desvelo más, a veces haciendo tarea, a veces en el celular... Pero siento que tengo sueño todo el día. Antes me levantaba a las cinco treinta para alcanzar a llegar a tiempo a la prepa, pero tenía como más energía. Ahora me levanto a las nueve o a veces más tarde, depende de la hora en que mi mamá se vaya, pero tengo sueño siempre, y ya cuando por fin me voy a dormir, no logro dormirme... Pienso una cosa y otra y nomás no me duermo hasta bien tarde, y por eso estoy tan cansada. (Mary, 15 años, 2. ${ }^{\circ}$ semestre, comunicación personal, 14.05.2O2O)

La aceptación y cumplimiento por parte de Mary de los roles y responsabilidades domésticas y de cuidado impuestas tras la situación de confinamiento facilitó la experiencia de poca tensión en su hogar. En su caso, su principal fuente de preocupación era el cumplimiento de sus propias tareas escolares.

[I: ¿Has sentido mayor tensión en tu casa?] La verdad es que no... Es que yo soy muy tranquila y me gusta estar en casa, entonces no me dicen nada [sus padres]. Por el contrario, siento que esta situación ha puesto como más apapachador a mi papá. El mes pasado me vio batallando con el celular que tenía para hacer la tarea y me dijo que me iba a comprar una laptop y yo pensé que no, porque ha tenido muchos problemas en su trabajo, pero la semana pasada me regaló una y... pues... yo sé que es su forma de decirme que me quiere y me apoya, porque sé que no es fácil para él sacar para comprarme eso a mí. (Mary, 15 años, 2. ${ }^{\circ}$ semestre, comunicación personal, 15.05.2O2O)

En el caso de Ely, los principales efectos del confinamiento han radicado en la disminución de su autonomía y de su vida social. Antes de la pandemia, Ely trabajaba en las tardes como asistente en el consultorio dental de un tío suyo. Por las noches acostumbraba salir a casa de sus amigos o a espacios públicos (cafés, bares, cine). Con el inicio de la pandemia dejó de trabajar y pasó a permanecer la mayor parte del día en casa. Cuando salía lo hacía siempre acompañada por sus padres. 
Mi vida sí ha cambiado mucho después de la pandemia. Antes salía sola más seguido, incluso me movía en transporte público y ahora, por prevención, pues trato de no salir, y si salgo, siempre es en coche, con mis papás (...). Cuando esto empezó, dejé de trabajar y sí me quedaba mucho en mi casa, pero ahora ya es demasiado, me causa mucha ansiedad estar encerrada. (Ely, 17 años, $6 .^{\circ}$ semestre, comunicación personal, 27.05.2O2O)

Aunque Ely también experimentó un aumento en sus responsabilidades domésticas, a diferencia de Mary, los ingresos más estables de su padre favorecieron la permanencia de la madre como cuidadora principal del hogar y que las responsabilidades domésticas fueran compartidas entre las mujeres de casa, todas mayores de 17 años, lo que convirtió estas actividades en una oportunidad de fortalecimiento de sus vínculos y de disminución del aburrimiento causado por el confinamiento. El ciclo de vida de la familia de Ely es otro elemento a su favor: a diferencia de Mary, no hay niños pequeños que requieran el cuidado de otros.

Bajamos recetas de internet y las probamos. Es como un juego, nunca había compartido cosas así con ellas, porque normalmente cada quien está en su pedo ${ }^{8}$. Ha sido divertido jugar con ellas, antes no lo hacíamos". (Ely, 17 años, $6 .^{\circ}$ semestre, comunicación personal, 26.05.2020)

La presencia de niños pequeños en los hogares aumentó la sensación de estrés en las participantes. La presencia de otro cuidador, con quien se pudiera compartir las tareas de cuidado, resultó fundamental en la experiencia de las jóvenes para aliviar la sensación de agobio.

Mis hermanitos sí me estresan porque se la pasan peleándose y gritando todo el día, y por eso también es que hago las tareas por la noche, cuando por fin ya todos se duermen, o en casa de mi novio. De día es un ruidero [sic] todo el tiempo... Le ayudo a mi mamá lo más que puedo, pero cuidarlos o ayudarles con la tarea es muy cansado, de repente ya me siento harta y solo quiero salir. Mi mamá me entiende y por eso no me pone problema en que me salga por las tardes. Además, tengo la excusa de que voy a hacer tareas [risas]. (Ana, 16 años, $4 .^{\circ}$ semestre, comunicación personal, 06.05.2020)

La presencia de conflictos previos en el hogar emergió en los relatos de las jóvenes como una condición que se exacerbó durante el confinamiento. Ello fue evidente en el caso de Lety ${ }^{9}$, para quien el confinamiento supuso perder la posibilidad de salir

8. Esta expresión coloquial es usada en México para referirse a que cada persona está ocupada en sus asuntos, deberes u obligaciones.

9. Lety es la menor de dos hermanos y vive con ambos padres y su hermano, tres años mayor que ella. 
del espacio doméstico donde vivía situaciones de violencia y, con ello, aumentó el control que ejercía su madre sobre sus consumos y prácticas de socialización, lo que se tradujo en emociones de impotencia y frustración.

Desde que esto empezó todo se ha puesto peor y no me deja salir [la madre], porque está paranoica con el virus, entonces no tengo oportunidad de echarme un cigarro ni qué decir de un churro [cigarro de marihuana] (...) está todo el tiempo encima de mí [la madre], que haga esto, que lleve aquello, que aquí y allá y si no le obedezco me llega a puños y patadas. Yo solo espero que esto termine pronto, porque no sé cuánto tiempo más pueda aguantarme. (Lety, 19 años, 6. ${ }^{\circ}$ semestre, comunicación personal, 22.06.2O2O)

La no conformidad de Lety frente a las aspiraciones de sus padres con respecto a sus estéticas, amigos y consumos fueron elementos que desde antes de la pandemia generaban tensión en el hogar, pero que durante el confinamiento se tornaron insostenibles. En estas circunstancias, Lety experimentó un aumento de sus niveles de ansiedad y su deseo de escapar de la vigilancia del mundo adulto para entrar en el espacio privado del consumo de sustancias psicoactivas con sus amigos; con ello se configuró un ciclo de tensión y conflicto pues, como era de esperarse, salir de la casa representaba una afrenta a la autoridad de la madre.

Todo el tiempo estoy enojada. Desde que me levanto pienso, "qué pinche vida” y enseguida mi mamá me grita o mi hermano me dice algo y entonces yo les grito, luego uno de los dos viene y me pega, me regreso a mi cama, lloro y solo pienso en salir... Es mi único pensamiento todo el tiempo que estoy en mi casa, "quiero estar afuera, quiero estar afuera, quiero salir de aquí”... No los aguanto. Mi hermano está todo el día echado, no hace nada y no le dicen nada, pero yo tengo que atenderlo, limpiar, cocinar, todo, solo porque soy mujer, por eso prefiero salirme, para alivianarme, respirar... (Lety, 19 años, $6 .^{\circ}$ semestre, comunicación personal, 21.04.202O)

El análisis de las experiencias de confinamiento de las cuatro jóvenes participantes del estudio muestra que ninguna característica de los hogares o de las jóvenes en sí misma es suficiente para constituir un tipo de experiencia particular del confinamiento. Es la superposición de condiciones de desigualdad lo que configura una red densa de causalidades que condiciona la experiencia del confinamiento. Al respecto, es importante subrayar que los recursos materiales e inmateriales (asociados a la calidad de los vínculos) de los hogares, así como los recursos emocionales de sus miembros, ayudaron a mitigar los impactos del confinamiento en las vidas de las jóvenes. Así mismo, no son las tareas en sí mismas las que generan la experiencia de la alienación en las jóvenes, sino el entramado de relaciones sociales al interior del 
hogar que llevan y sostienen el desempeño de dichas tareas (Mora; Pujal-Lombart, 2018), y a través de las cuales las jóvenes les asignan un significado particular, bien como oportunidad para fortalecer los vínculos o como expresión de alienación, discriminación o exclusión social.

\section{De la escuela a la obra. Varones y el mandato de la proveeduría económica}

Como lo mencionamos, el cambio más importante en las rutinas de los jóvenes varones participantes de este estudio fue el aumento en sus actividades laborales remuneradas. Estas experiencias de rápida inserción en actividades manuales de baja calificación en un mercado laboral precarizado e informal, deben leerse en el contexto más amplio de la situación del empleo en Aguascalientes durante la pandemia.

Según el Instituto Mexicano del Seguro Social (IMSS, 2020), entre febrero y julio se perdieron un total de 17135 empleos formales y 6723 informales. Todos los varones jóvenes participantes en el estudio reportaron pérdida de los empleos de algún miembro de la familia y disminución de los ingresos del hogar, situación que los llevó a ocuparse en la actividad que estuviera disponible para ellos; en este caso, fue el trabajo informal en la obra como ayudantes de albañil, actividad a través de la cual devengaban entre \$ 750 y 1,00o MXN por semana (entre 37 y 45 USD).

Antes de la pandemia, Paco trabajaba los fines de semana en un salón de fiestas, en labores amplias que abarcaban limpiar y ordenar el lugar, ayudar a poner y quitar la decoración, y realizar alguna compra urgente. Este trabajo le permitía dedicarse entre semana a sus tareas académicas. En la mañana iba a clases y a partir de las cuatro de la tarde dedicaba su tiempo a hacer tareas, escuchar música y ver televisión. La escuela era el principal espacio de socialización con pares, pues no tenía amigos en su vecindario debido a la presencia de pandillas y a la alta conflictividad social que él percibía. Tras el confinamiento, Paco perdió su trabajo en el salón de eventos y pasó a emplearse en la obra. Desde entonces, trabajó de lunes a viernes de siete de la mañana a siete de la tarde. El cambio más drástico sentido por él fue la falta de espacios de ocio.

Solo salgo a trabajar y a la tienda, en el salón de eventos no ha habido eventos, pero ahorita estoy dando mantenimiento, si se ocupa, y buscando chambitas que me salen en la obra. El tiempo se va por las tareas, el trabajo y además estoy ayudando en la construcción y remodelación de la casa de mis tíos; es pesado, pero me gusta estar ocupado y sentirme útil. (Paco, 16 años, 4 . $^{\circ}$ semestre, comunicación personal, 08.05.2020)

La experiencia de la ocupación total en detrimento de los espacios de ocio se repitió en Carlos, quien antes del confinamiento pasaba sus tardes con su grupo de 
amigos. Al salir de la escuela se paseaba con sus compañeros de clase por la plaza principal del municipio (ubicada a unos 30 minutos caminando de la escuela) con el plan de echarse unos tabacos, y pasar un tiempo de convivencia antes de llegar a casa, alrededor de las cuatro de la tarde. Al atardecer, volvía a salir a casa de alguno de sus compañeros para grabar canciones, armar rimas o simplemente echar desmadre hasta las nueve de la noche, cuando regresaba a casa. Con el inicio de la pandemia, estos espacios de esparcimiento pasaron a ser ocupados por el trabajo en la obra.

En casa no estoy, tengo que trabajar mucho... El COVID para mí no existe, no se puede, hay que chambear para tragar [risas] (...). Mi dinámica si ha cambiado mucho, me siento muy estresado, con dolor de cabeza y con muchos trabajos. Ya no hay tiempo para verme con mis cuates, ni para hacer nada distinto a chambear. Además, si están en la calle, pasan los militares y te chingan, entonces ni pa' donde hacerse. (Carlos, 17 años, $6 .^{\circ}$ semestre, comunicación personal, 08.05.2020)

Si bien en algunos casos - como los de Carlos y Pepe-el alto número de dependientes en sus hogares, aunado a la condición de desempleo de los adultos, generaron condiciones claras de presión económica, no todos los participantes vivieron tales constreñimientos de manera tan intensa; sin embargo, pasaron a ocupar todo su tiempo en la obra debido, como en el caso de Paco, a su necesidad de sentirse útil, de no ser una carga y cumplir con los valores de la masculinidad hegemónica (Connell; Messerschmidt, 2005).

Pepe y Carlos comparten la experiencia de un padre en situación de abuso de sustancias y una madre como responsable principal del sostenimiento económico del hogar. En estas condiciones, responder como hombre de la casa significa apoyar a la madre. En el caso de Paco, la condición etaria de sus tíos (mayores de 65 años) aparece en su relato como el principal factor que lo motivó a incrementar sus horas de trabajo durante la pandemia. Los tres jóvenes varones comparten una percepción de vulnerabilidad de sus cuidadores que, en el contexto de pandemia y ante la posibilidad de quedarse en casa sin hacer nada, los lleva a buscar trabajo en la obra de manera intensiva.

No quiero que me sientan [sus tíos] como una carga. Yo trabajo para poder pagar mis cosas, mis cuadernos y las cosas que me piden en la escuela. No es que ellos me obliguen o no me den lo que necesito, es que no me gusta pedirles. (Paco, 16 años, 4 . $^{\circ}$ semestre, comunicación personal, 25.05.2020)

El ser o convertirse en una carga pareciera connotar la pérdida del honor para estos jóvenes varones. El incumplir con el mandato de la proveeduría económica, 
aun cuando solo sea una posibilidad, pareciera causar en estos varones jóvenes una descalificación profunda de su ser, que los incita de manera natural a ocuparse en el mercado de trabajo. Así, quedarse en casa sin aportar pareciera ir en contravía de la hombría de estos jóvenes, de modo que, ante la pérdida de la escuela como espacio de socialización y construcción de la identidad, la proveeduría económica y el trabajo se convirtieron en su principal escenario de construcción de identidades.

La condición etaria añadió una capa adicional de desigualdad pues los jóvenes no tenían la experiencia o habilidades necesarias para acceder a una mejor ocupación, aun en el espacio de la obra, por lo que su capital fue su cuerpo, su capacidad de trabajo, su resistencia o su fuerza. En la obra ocuparon la posición de ayudantes de albañil o chalanes - que corresponde al lugar más bajo-, a quienes se les asigna la realización de actividades que requieren mayor esfuerzo físico. Adicionalmente, ser menores de edad en la obra conllevó una posición de subordinación a los varones adultos con los que socializaban en este espacio; esto añade otra dimensión de la experiencia del aguante ya no solo en términos del esfuerzo físico, sino también en relación con las burlas y la carrilla ${ }^{10}$.

\section{I: ¿Cómo te sientes en la obra?}

P: Bien [sonrisa nerviosa y mirada evasiva]

I: Ándale, cuéntame cómo es la vida en la obra

P: [mirada evasiva], pues... ¿qué quiere que le diga?... normal, es puro trabajar, ir de arriba pa' bajo, todo el día, eso es... Cargar, descargar, hacer lo que se ocupe, si es cansado, pero uno se va acostumbrando y ya después no se hace tan pesado, es nomás aguantar

I: ¿y qué tal los compañeros?, ¿cómo te llevas con ellos?

P: Pues... Si son pesadas sus carrillas, pero te acostumbras también (...) Te aguantas porque si te quejas es peor [sonrisa tímida]. (Pepe, 17 años, $2 .^{\circ}$ semestre, comunicación personal, 15.05.2020)

La vinculación laboral en los tres casos estudiados estuvo mediada por familiares mayores que trabajaban de tiempo completo como albañiles, quienes invitaron a los jóvenes a la obra y facilitaron su contratación. De este modo, la presencia de familiares (tíos, primos, padre) que trabajaban previamente en la obra, no solo favoreció el acceso a saberes y experiencias previas en torno a los oficios a realizar, sino que operó como una extensión de vínculos de confianza y credibilidad a través de los cuales los jóvenes accedieron al trabajo. Sin embargo, la vinculación laboral 
de estos jóvenes a través de un adulto (padre y tíos, principalmente) extendió al espacio laboral la posición de subordinación que ocupaban en el espacio doméstico.

A través de su desempeño como ayudantes de albañil, los jóvenes demuestran frente a los otros varones con quienes comparten su espacio social (familiares, vecinos, amigos, compañeros de escuela) su valía en tanto varones-proveedores, y en esa medida accedieron a prestigio y estatus en sus hogares, pero en el espacio público, "ámbito privilegiado en el cual las acciones se despliegan para que sean vistas y evaluadas" (Rosas, 2008:36).

Así, la experiencia de trabajo en la obra constituyó para estos jóvenes varones un escenario clave de socialización y de aprendizaje de las maneras legítimas de ser hombre. A través de la experiencia en la obra, los jóvenes se expusieron a formas particulares de vivir y performar su masculinidad; ello suponía, entre otras cosas, no quejarse frente al cansancio ni ante la incomodidad que les pudieran causar las bromas de sus compañeros, y saber cuándo responder o callar frente a la carrilla. Lo anterior les permitió sobrevivir en un mundo de varones, en la medida en que evitaban exponer sus vulnerabilidades (Seidler, 1995, como se citó en Rosas, 2008).

Si bien es cierto que los hogares de los participantes varones enfrentaron una reducción de sus ingresos como consecuencia de la pandemia por COVID-19-motivador principal para salir al mercado laboral-, encontramos también que los varones, a diferencia de las mujeres, no encontraban un lugar en el espacio doméstico, donde se sentían especialmente incómodos. Pareciera como si antes y durante la pandemia la casa no fuera un espacio para ellos y que, como ocurrió en dos de los tres casos aquí analizados, la calle fuese el espacio principal de sus dinámicas de sociabilidad:

Nunca me ha gustado quedarme en casa. Siempre hay mucha gente, mucho calor, y nomás me estreso. Prefiero ir a casa de primos, de unos cuates que tengo ahí cerca o estar cotorreando en la calle (...) la casa nomás es para dormir [risas]. (Carlos, 17 años, 6. ${ }^{\circ}$ semestre, comunicación personal, 09.05.2020)

De esta manera salir a trabajar puede entenderse en el caso de estos jóvenes no solo como una estrategia de sobrevivencia económica, sino también como una manera masculina de responder a la incertidumbre y a la suspensión de la cotidianidad generada por la contingencia. El trabajo sin descanso se constituyó en un recurso que les permitió escapar de la realidad de sus hogares e incluso de sí mismos, entregándose a la templanza que exige el trabajo manual, lo que favoreció cierto distanciamiento de la experiencia emocional que supuso el confinamiento.

Es que el trabajo es pesado y ya llego a las nueve más o menos y la neta llego agotado, ceno con mis tíos y me duermo luego, luego porque no aguanto más... Me paro muy 
temprano, a las cinco ya estoy en pie y estoy todo el día chambeando, de pie. Sólo me siento cuando comemos. En la noche ya los pies me duelen y solo quiero dormirme, no hay tiempo para más. (Paco, 16 años, $4 .{ }^{\circ}$ semestre, comunicación personal, 28.06.2020)

Por otro lado, con la pandemia la calle también quedó suspendida como espacio de sociabilidad; y pasó a estar ocupada principalmente por agentes de seguridad del Estado que patrullaban las calles día y noche, asegurando la menor presencia posible de personas en el espacio público. Ha sido ampliamente documentado cómo la criminalización de las juventudes empobrecidas es una práctica muy consolidada en México (Reguillo, 2004; Valenzuela, 2015), que se vio reforzada y legitimada en el contexto de pandemia, aumentando las tensiones de los jóvenes varones frente al ejercicio de su autonomía y de sus identidades. Por ejemplo, Pepe fue detenido por la policía al ser sorprendido usando sustancias psicoactivas en la vía pública y fue enviado a tratamiento forzado, por lo que no pudo regresar a la escuela.

De acuerdo con registros de la institución escolar de 153 jóvenes que cursaban el sexto semestre al inicio de la pandemia (86 varones y 67 mujeres), 18 de ellos (11 hombres y 7 mujeres) no concluyeron el ciclo escolar, lo que representa una pérdida del $13 \%$ del total de inscritos ( $13 \%$ de los varones vs. $10 \%$ de las mujeres). De los siete jóvenes participantes del estudio, dos desertaron faltando pocos meses para terminar el ciclo escolar. Al hacer la comparación con el ciclo anterior, las autoridades escolares reportan que la deserción al finalizar el ciclo escolar 2019-2020 aumentó un $20 \%$ frente al nivel reportado en el ciclo 2018-2019.

\section{Reflexiones finales}

Los relatos aquí presentados evidenciaron el impacto del confinamiento sobre el uso del tiempo en los jóvenes pobres y escolarizados de Aguascalientes. Ante la pérdida de empleos e ingresos, la principal estrategia de sobrevivencia en los hogares pobres fue recurrir a la mano de obra disponible, en particular a la de los jóvenes de ambos sexos, pero la manera en que ello se materializó tuvo importantes diferencias asociadas al género. Mientras los varones se vieron forzados a incorporarse al mercado laboral en condiciones precarias e inestables, bajo la figura de ayudante de albañil, las mujeres se vieron forzadas a pasar más tiempo en sus casas, donde estaban a cargo de labores domésticas y de cuidado no remuneradas. De este modo, los relatos muestran cómo la sobrevivencia económica de los hogares estuvo asegurada por la capacidad de trabajo de los jóvenes, lo que en el corto plazo afectó negativamente su salud mental, el ejercicio de su autonomía y su permanencia en la escuela. En 
el largo plazo podría significar la reproducción intergeneracional de la pobreza por los efectos de la escolaridad trunca, así como la vinculación precaria y temprana a mercados laborales informales.

La reclusión de las mujeres en el espacio doméstico y la imposición de las tareas domésticas resultan problemáticas no solo por la experiencia compartida de la casa como obligación, sino porque los roles de género estructuran y orientan a los sujetos regulando sus interacciones, y promueven ciertos tipos de relación entre los miembros del hogar que normalizan y perpetúan la subordinación de las jóvenes (Aguirre, 2009; De Oliveira; Ariza, 2000; Eisenstein, 1999; Valenzuela, 2003). En segundo lugar, la asignación exclusiva del trabajo doméstico a las jóvenes se convierte en un obstáculo concreto y determinante para su integración en los procesos productivos y políticos (De Barbieri, 1991), lo mismo que para una mejora sustantiva en su calidad de vida, en tanto limita el acceso de las jóvenes a recursos económicos propios, a decidir sobre los recursos que se generan en el hogar y a beneficiarse de estos (Aguirre, 2009; De Barbieri, 1991; De Oliveira; Ariza, 200o; Eisenstein, 1999; Valenzuela, 2003; ONU Mujeres; Cepal, 2020).

La incorporación precaria de los varones jóvenes al mercado laboral también resulta problemática, en tanto refuerza las condiciones de reproducción intergeneracional de la pobreza (Mora; De Oliveira, 2011). Adicionalmente, la subordinación generacional bajo la cual los jóvenes de este estudio se incorporaron al mercado laboral reproduce los roles tradicionales de género, lo cual obstaculiza los procesos de cambio cultural que también se promueven desde la escuela.

Tanto mujeres como varones tuvieron que reducir los tiempos destinados a las labores escolares para cumplir con los nuevos roles asignados. Esto llevó a que la experiencia de la escuela fuese percibida como carga y a una sobresaturación de sus tiempos, con pocos espacios para el ocio. En estos contextos, una mayor proporción de varones en comparación con las mujeres abandonaron la escuela, interrumpiendo sus trayectorias educativas. Este diferencial podría denotar que el espacio doméstico, aun con todas las limitaciones que supone, es más compatible con las actividades escolares que el espacio del trabajo remunerado por fuera del hogar. En el presente estudio es importante enfatizar que los varones participantes accedieron a trabajos manuales de baja calificación que requerían uso intensivo del cuerpo, los cuales les causaban agotamiento extremo al final de la jornada, situación que impedía que los varones destinaran tiempo a realizar actividades escolares al llegar a sus casas. Convendría poner a prueba esta hipótesis con nuevo material empírico que permitiera comprender mejor cómo el espacio doméstico se compatibiliza con las actividades escolares, y cuáles son las barreras para el desempeño académico que generan los espacios de trabajo remunerado a los que accedieron los varones del estudio. 
Con la suspensión de la escuela, la reclusión en el espacio doméstico y el ingreso temprano en el mercado laboral, los participantes en el estudio vieron limitado el ejercicio de su autonomía debido, por un lado, a la reducción de los espacios de ocio; y por otro, a la mayor presencia militar en las calles. Antes de la pandemia, la calle ofrecía un espacio para ser ellos mismos, para cotorrear y transgredir. Con el confinamiento, las calles quedaron desiertas y fueron ocupadas por Policía y Guardia Nacional, por lo cual los jóvenes que se resistían a quedarse en casa quedaron expuestos al despliegue de medidas punitivas por parte del Estado, desde las cuales ciertas prácticas y expresiones identitarias son estigmatizadas y criminalizadas, lo que aumentó el descontento y la tensión. Al respecto resulta fundamental replantear la presencia del Estado en las colonias populares y el control punitivo de la pobreza que se ejerce a través de la presencia excesiva de fuerza militar en estos espacios de la ciudad.

La doble jornada, en conjunto con la situación de incertidumbre que generó la pandemia, los constreñimientos económicos que enfrentaron los hogares y la mayor represión y pérdida de espacios de autonomía, contribuyeron a que los jóvenes experimentaran problemas de salud mental bajo la forma de dificultad para conciliar el sueño; cansancio crónico; dolor de cabeza; irritabilidad; depresión, y aumento en la intensidad y frecuencia de uso de sustancias psicoactivas. Las estrategias a través de las cuales los jóvenes lidiaron con estas dificultades estuvieron mediadas nuevamente por los recursos que ofrecía la familia y los apoyos que brindó la escuela. En estas condiciones, los relatos que aquí se presentaron ejemplifican cómo la pandemia por la COVID-19 aumentó las condiciones de desigualdad social de los hogares en México, así como las condiciones de inequidad de género entre hombres y mujeres jóvenes.

Los hallazgos muestran que la escuela pública, aun con sus carencias y deficiencias, toma vital importancia en el caso de los jóvenes pobres, al ser una de las pocas instituciones públicas que ofrecen protección en un contexto plagado de inequidades de todo tipo, incluidas las de género. Como bien lo plantea Reguillo (2004), el drama de la crisis estructural y sus impactos en las dinámicas cotidianas y en las biografías de los sujetos juveniles pasa por la imposibilidad de acceder o mantener activos que se traduzcan en insumos para mejorar o mantener sus condiciones de vida. La supresión de la escuela como espacio de encuentro y formación coadyuvó a la descapitalización de los jóvenes del presente estudio.

La historia de cómo siete jóvenes estudiantes de preparatoria de un municipio suburbano de Aguascalientes vivieron la contingencia por COVID-19 permite comprender los mecanismos a través de los cuales se acrecienta y reproduce la desigualdad en las poblaciones vulnerabilizadas. Con esto se subraya la urgencia de diseñar 
políticas públicas que respondan a las maneras en que se intersectan el género, la edad y el nivel socioeconómico.

El reparto de responsabilidades al interior de los hogares, así como la división sexual del trabajo tan tradicional que aquí encontramos, deben leerse en el marco de las relaciones Estado-familia-mercado (Aguirre, 2009). Los datos aquí analizados muestran que, debido al debilitamiento de las políticas de bienestar social que se ha vivido en México desde la década de 1990, la responsabilidad principal del bienestar de los sujetos recae sobre los hogares. En esa medida, es indispensable fortalecer las políticas de bienestar social que favorezcan la protección de las familias durante contingencias como las vividas por la COVID-19. El cambio cultural necesario para flexibilizar la división sexual del trabajo al interior de los hogares, lo mismo que para ampliar los derechos sociales y económicos de los jóvenes pobres en México, necesita condiciones materiales para poder ejecutarse; y es responsabilidad del Estado garantizarlas.

\section{Referencias}

Aguirre, Rosario (2009). Uso del tiempo y desigualdades de género en el trabajo no remunerado. En Las bases invisibles del bienestar social. El trabajo no remunerado en Uruguay (pp. 23-85), editado por Rosario Aguirre. Montevideo: Unifem.

Batthyány, Karina (2009). Cuidado de personas dependientes y género. En Las bases invisibles del bienestar social. El trabajo no remunerado en Uruguay (pp. 87-123), editado por Rosario Aguirre. Montevideo: Unifem.

Busso, Gustavo (junio, 2001). Vulnerabilidad social: nociones e implicancias de politicas para Latinoamérica a inicios del siglo XXI. Trabajo presentado en Seminario Internacional "Las Diferentes Expresiones de la Vulnerabilidad Social en América Latina y el Caribe", Santiago de Chile.

Casique, Irene (2008). Participación en el trabajo doméstico de hombres y mujeres en México. Papeles de población, 14(55), 173-200. Recuperado de http://www.scielo.org.mx/scielo. php?pid=S1405-74252008000100008\&script=sci_abstract

Chase, Susan E. (2005). Narrative Inquiry. Multiple Lenses, Approaches, Voices. En Collecting and interpreting qualitative materials (pp. 57-94), editado por Norman Denzin e Yvonna Lincoln. Thousand Oaks: Sage Publications.

Consejo Nacional de Evaluación de la Política de Desarrollo Social - Coneval (202Oa). La crisis sanitaria generada por la COVID-19 y sus consecuencias económicas ponen en riesgo avances en desarrollo social y puede afectar en mayor medida a grupos vulnerables [Comunicado de 
prensa]. Recuperado de https://www.coneval.org.mx/SalaPrensa/Comunicadosprensa/ Documents/2020/Comunicado_o6_POLIITICA_SOCIAL_EN_CONTEXTO_COVID_19.pdf

Consejo Nacional de Evaluación de la Política de Desarrollo Social - Coneval (2O2Ob). La política social en el contexto de la pandemia por el virus SARS-CoV-2 (COVID-19) en México. Recuperado de https://www.coneval.org.mx/Evaluacion/IEPSM/Documents/Politica Social_COVID-19.pdf

Consejo Nacional de Evaluación de la Política de Desarrollo Social - Coneval (2020c). Pobreza municipal 2010, Aguascalientes. Recuperado de https://www.coneval.org.mx/coordinacion/ entidades/Aguascalientes/Paginas/pob_municipal.aspx

Creswell, John (1998). Qualitative Inquiry and Research Design: Choosing Among Five Traditions. Thousand Oaks: Sage.

Connell, Robert W.; Messerschmidt, James (2005). Hegemonic Masculinity: Rethinking the Concept. Gender \& Society, 19(6), 829-859. https://doi.org/10.1177/o891243205278639

De Barbieri, Teresita; De Oliveira, Orlandina (1989). Reproducción de la fuerza de trabajo en América Latina: Algunas hipótesis. En Las ciudades latinoamericanas en la crisis (pp.19-29), compilado por Martha Schteingart. Ciudad de México: Trillas.

De Barbieri, Teresita (1991). Los ámbitos de acción de las mujeres. Revista Mexicana de Sociología, 53(1), 203-224. https://doi.org/10.2307/3540834

Damián, Araceli (2003). La pobreza de tiempo: una revisión metodológica. Estudios Demográficos y Urbanos, 18(52), 127-162. http://dx.doi.org/10.24201/edu.v18i1.1173

De Oliveira, Orlandina; Ariza, Marina (200o). Género, trabajo y exclusión social en México. Estudios Demográficos y Urbanos, 15(43), 11-33. http://dx.doi.org/10.24201/edu.v15i1.1065

Eisenstein, Zillah (1999). Constructing a Theory of Capitalist Patriarchy and Socialist Feminism. Critical Sociology, 25(2-3), 196-217. https://doi.org/10.1177/o8969205990250020901

Fuster, Doris (2019). Investigación cualitativa: Método fenomenológico hermenéutico. Propósitos y Representaciones, 7(1), 201-229. http://dx.doi.org/10.20511/pyr2019.v7n1.267

Gaxiola-Romero, José Concepción; González-Lugo, Sandybell (2019). Apoyo percibido, resiliencia, metas y aprendizaje autorregulado en bachilleres. Revista Electrónica de Investigación Educativa, 21(eo8), 1-10. https://doi.org/10.24320/redie.2019.21.eo8.1983

Hochschild, Arlie Rusell (2008). La mercantilización de la vida íntima. Apuntes de la casa y el trabajo. Madrid: Katz.

Instituto Nacional de Estadística, Geografía e Informática - Inegi (2020). Encuesta Nacional de Ocupación y Empleo Nueva Edición. Tercer trimestre de 202O. Recuperado de https://www. inegi.org.mx/contenidos/programas/enoe/15ymas/doc/enoe_n_presentacion_ejecutiva_ trim3.pdf 
Instituto Nacional de Estadística, Geografía e Informática - Inegi (2021). Censo de población $y$ vivienda de México. Indicadores sociodemográficos básicos. Recuperado de https://www. inegi.org.mx/programas/ccpv/202O/

Instituto Mexicano del Seguro Social - IMSS (2020). Registro de empleos formales. Recuperado de http://www.imss.gob.mx/prensa/archivo/202012/827

Martínez, Carolina (2012). El muestreo en investigación cualitativa. Principios básicos y algunas controversias. Ciência \& Saúde Coletiva, 17(3), 613-619. https://doi.org/10.1590/ S1413-81232012000300006

Martínez, Mario; Ferraris, Sabrina (2017). Trabajo y masculinidad: el rol del proveedor en el México urbano. En Generaciones, cursos de viday desigualdad social en México (pp.322-341), coordinado por Marie-Laure Coubés, Patricio Solís y María Eugenia Cosio-Zavala. Ciudad de México: El Colegio de México/El Colegio de la Frontera Norte.

México Cómo Vamos (2020). El impacto del Covid-19 sobre el empleo formal en los estados. Recuperado de https://mexicocomovamos.mx/publicaciones/2020/o7/el-impacto-delcovid-19-sobre-el-empleo-formal-en-los-estados/

Mora, Enrico; Pujal-Llombart, Margot (2018). El cuidado: más allá del trabajo doméstico. Revista Mexicana de Sociología, 8o(2), 445-469. Recuperado de http://www.scielo.org.mx/ $\mathrm{pdf} / \mathrm{rms} / \mathrm{v} 8 \mathrm{on} 2 / \mathrm{o188-2503-rms-80-02-445.pdf}$

Mora, Minor; De Oliveira, Orlandina (2011). Jóvenes Mexicanos en medio de la crisis económica: los problemas de la integración laboral. Sociedade e Estado, 26(2), 373-401. https://doi. org/10.1590/So102-69922011000200017

Entidad de las Naciones Unidas para la Igualdad de Género y el Empoderamiento de las Mujeres - ONU Mujeres; Comisión Económica para América Latina - Cepal (2020). Cuidados en América Latina y el Caribe en tiempos de COVID-19. Hacia sistemas integrales para fortalecer la respuesta y recuperación. Recuperado de https://repositorio.cepal.org/ bitstream/handle/11362/45916/190829_es.pdf

Ospina-Escobar, Angélica; Chávez-Llamas, Nancy (2020). Bien Puestos. Una intervención para la reducción de riesgos y daños asociados al uso de sustancias en jóvenes de preparatoria. Cuadernos de Trabajo del Monitor del Programa de Política de Drogas (CIDE), 35, 1-43. Recuperado de https://politicadedrogas.org/PPD/documentos/20210106_111911_ct35_ bien_puestos_ppd_1.pdf

Pateman, Carole (1996). Críticas feministas a la dicotomía público/privado. En Perspectivas feministas en teoría política (pp.31-52), coordinado por Carmen Castells. Barcelona: Paidós.

Pedrero-Nieto, Mercedes (2004). Sabia virtud de conocer el tiempo. El uso del tiempo en función del género: análisis comparativo entre México y Europa. Revista de Economía Mundial, 1O(11), 77-101. Recuperado de http://rabida.uhu.es/dspace/bitstream/handle/10272/447/ b1376676.pdf? sequence $=1$ 
Reguillo, Rossana (2004). La performatividad de las culturas juveniles. Estudios de juventud, 64(4), 49-56. Recuperado de http://www.injuve.es/sites/default/files/64tema4.pdf

Riley, Matilda (1987). On the significance of age in sociology. American Sociological Review, 52(1), 1-14. https://doi.org/10.2307/2095388

Rosas, Carolina (2008). Varones al sol de la migración. Migración internacionaly masculinidades de Veracruz a Chicago. Ciudad de México: El Colegio de México.

Scuro-Somma, Lucía (2009). Pobreza y desigualdades de género. En Las bases invisibles del bienestar social. El trabajo no remunerado en Uruguay (pp. 125-153), editado por Rosario Aguirre. Montevideo: Unifem.

Secretaría de Educación Pública (2020). Boletín No.196 Convivirán, en el futuro, modelo de educación presencialy a distancia:Esteban Moctezuma Barragán. Recuperado de https://www. gob.mx/sep/es/articulos/boletin-no-196-conviviran-en-el-futuro-modelo-de-educacionpresencial-y-a-distancia-esteban-moctezuma-barragan?idiom=es

Fondo de las Naciones Unidas para la Infancia - Unicef (9 de julio de 2020). UNICEF: COVID-19 impacta más a hogares con niños y adolescentes [comunicado de prensa]. Recuperado de https://www.unicef.org/mexico/comunicados-prensa/unicef-covid-19-impacta$\mathrm{m} \% \mathrm{C}_{3} \%$ A1s-hogares-con-ni\%C3\%B1os-y-adolescentes

Valenzuela, José Manuel (2015). El sistema es antinosotros. Culturas, movimientos y resistencias juveniles. Tijuana, México: El Colegio de la Frontera Norte/Universidad Autónoma Metropolitana/Gedisa.

Valenzuela, María Elena (2003). Desigualdades de género y pobreza en América Latina. Santiago de Chile: Organización Internacional del Trabajo.

Yin, Robert K. (2003). Case Study Research: Design and Methods. Thousand Oaks: Sage. 